\title{
AS REPRESENTAÇÕES SOCIAIS DO TRABALHO ENTRE ADOLESCENTES APRENDIZES - UM ESTUDO PILOTO
}

\author{
ADOLESCENT APPRENTICES' SOCIAL REPRESENTATIONS OF \\ WORK - A PILOT STUDY
}

Elsa de Mattos*

Antonio Marcos Chaves ${ }^{* *}$

\begin{abstract}
Mattos Ed, Chaves AM. As representações sociais do trabalho entre adolescentes aprendizes um estudo piloto. Rev Bras Crescimento Desenvolv Hum 2006; 16(3):66-75.

Resumo: O presente estudo investigou as representações sociais de adolescentes aprendizes sobre o trabalho e a relação entre trabalho e estudo. Setenta jovens com idades entre 15 e 18 anos, participantes de um programa de aprendizagem desenvolvido em uma ONG situada em Salvador (Bahia), responderam um questionário aberto contendo três questões abertas: Para você, o que é trabalho? O que significa para você ser adolescente e trabalhar? Como é para você estar estudando e trabalhando ao mesmo tempo? As respostas foram submetidas à análise de conteúdo temática. Os resultados apontam para três tipos de representação social do trabalho entre adolescentes aprendizes, relacionadas aos resultados do trabalho, às atitudes frente ao trabalho e ao desenvolvimento pessoal. Dentre os resultados do trabalho destacam-se elementos como a obtenção de salário e o cumprimento de tarefas. As atitudes mais significativas referem-se à responsabilidade e ao desenvolvimento da competência. No que se refere ao desenvolviemento pessoal, aparecem aspectos ligados à aprendizagem e à aquisição de experiência. A relação entre trabalho e estudo aparece como algo complexo, que exige um esforço de conciliação por parte dos jovens, mas não tem necessariamente uma conotação negativa.
\end{abstract}

Palavras-chave: Adolescente. Desenvolvimento do Adolescente. Trabalho. Trabalho de Menores.

\section{INTRODUÇÃO}

A inserção laboral infanto-juvenil tem sido objeto de preocupação recente de governos, organismos internacionais e organizações não governamentais. O centro dos debates tem focado, sobretudo, a problemática do trabalho de crianças em situação de pobreza que encontram meios de subsistência através da inserção no mercado informal, como forma de garantir a subsistência própria e de suas famílias. Sem negar a importância de buscar soluções coletivas para a questão do trabalho infantil, de forma a permitir que as crianças brasileiras tenham direito à infância, é importante tratar de forma diferenciada a situação do adolescente, que já encontra respaldo legal para o exercício laboral em nosso país.

Do ponto de vista da legislação brasileira, um conjunto de medidas vem regulamentando as condições da inserção dos adolescentes no mundo do trabalho, entre as quais se destacam o ECA (Estatuto da Criança e do Adolescente), lei federal de 1990, e a Lei da Aprendizagem (Lei 10.097/2000). Essas medidas asseguram à criança e ao adolescente o cumprimento dos direitos presentes na Constituição Federal, procurando defendê-los da exploração e permitindo a

\footnotetext{
* Programa de Pós-Graduação em Psicologia (UFBA). Rua Aristides Novis, 105, ap.1001B - Federação, CEP: 40.210730 Salvador (BA). Email: elmattos@atarde.com.br

** Professor do Programa de Pós-Graduação em Psicologia (UFBA). Endereço para correspondência: Av. Otávio Mangabeira, 11.881, M-406, CEP: 41.650-000 Salvador(BA). Email: amchaves@ufba.br.
} 
entrada no mercado de trabalho a partir dos 16 anos. A Lei da Aprendizagem, instituída em 2000, complementa o ECA, assegurando que adolescentes e jovens com idade entre 14 e 24 anos podem exercer atividade produtiva em horário determinado, com continuidade dos estudos e também com todas as garantias trabalhistas e previdenciárias dos demais trabalhadores empregados (tais como férias, aviso prévio, $13^{\circ}$ salário, FGTS, etc), desde que recebam capacitação específica para essa atividade.

A criação de condições para inserção qualificada de adolescentes e jovens no mundo do trabalho, especialmente daqueles em situação de vulnerabilidade social, é essencial para a construção de um país mais justo e igualitário. Estudos recentes realizados no Brasil trazem diferentes enfoques e concepções sobre o trabalho infanto-juvenil. Enquanto algumas pesquisas enfatizam os aspectos negativos desse tipo de trabalho, outras mostram o lado positivo da inserção laboral precoce.

Conseqüências negativas foram apontadas por Oliveira, Fisher, Martins, Teixeira \& Sá3, Fischer, Martins, Oliveira, Teixeira, Latorre, \& Cooper $^{4}$ e Martins, Fischer, Oliveira, Teixeira, Costa, Marinho, Perestrelo \& Latorre ${ }^{5}$. Martins e colaboradores ${ }^{3}$, que registram débitos de sono, alterações no estado de ânimo, sobrecarga de tarefas e o afastamento da escola entre os adolescentes que trabalham. Essas pesquisas destacam os riscos bio-psico-sociais que o trabalho precoce acarreta, argumentando que crianças e adolescentes que trabalham deixam de vivenciar experiências que são essenciais nesse momento da vida. Outros estudos, entretanto, indicam que o trabalho é importante para o adolescente, pois além de ampliar os rendimentos da família, favorece o desenvolvimento cognitivo e emocional nessa fase da vida, possibilitando a aquisição de novas habilidades, o desenvolvimento da autonomia e da responsabilidade. Os pesquisadores também destacam que o trabalho atua como forma complementar de socialização entre adolescentes e jovens, ao lado da escola, da família e do grupo de pares ${ }^{6}$.

Recentemente, alguns estudos têm buscado compreender as representações que esses atores sociais constroem sobre a atividade laboral. Em estudo realizado com alunos trabalhadores de uma escola pública, Alves-Mazzotti ${ }^{4}$ relatou que os jovens, em geral, percebem o trabalho de maneira positiva, como uma atividade que lhes possibilita ajudar à família, ao tempo em que os prepara para o futuro. Nessa linha, a autora defende que a atividade laboral pode contribuir para que o adolescente desenvolva sentimentos de independência, auto-valorização e respeito, ou seja, que ela permite a formação de uma autoimagem positiva. Oliveira, Fischer, Amaral, Teixeira \& Sá ${ }^{5}$ também destacam o predomínio de elementos positivos nas representações do trabalho entre adolescentes do ensino médio de uma escola pública de São Paulo. No entanto, em pesquisa feita com adolescentes trabalhadores $\mathrm{e}$ não trabalhadores de duas cidades de São Paulo, os autores afirmam que, quando associado ao estudo, o trabalho é representado de forma contraditória, refletindo um campo de possibilidades e de impossibilidades, mas que, ainda assim é legitimado pelos jovens ${ }^{5}$.

O conjunto das pesquisas demonstra que, embora o trabalho apresente riscos para a saúde bio-psico-social dos adolescentes, essa atividade não pode ser tratada de forma homogênea, considerando somente suas conseqüências negativas. Em alguns casos, o trabalho pode representar uma experiência positiva e relevante para adolescentes e jovens, desde que sejam asseguradas condições que possibilitem o exercício laboral sem prejuízo à saúde, escolaridade e lazer. A maioria das pesquisas realizadas até o momento, no entanto, focou adolescentes que exercem atividades precárias, sem respaldo legal e atuando no mercado informal. Outros estudos, realizados com jovens que exercem atividades mais bem estruturadas podem trazer novas contribuições sobre o tema.

É necessário aprofundar a compreensão sobre as representações sociais dos adolescentes que trabalham em condições mais favoráveis, como é o caso daqueles que contam com o repaldo da Lei da Aprendizagem. Esses estudos podem informar políticas públicas voltadas para inserção social de adolescentes e jovens em situação de vulnerabilidade social. Além disso, a ques- 
tão do trabalho precoce, em espacial o trabalho de adolescentes e jovens, precisa ser tratada de forma específica pelos pesquisadores, já que essa época da vida está associada à redefinição dos papéis sociais, à construção da identidade pessoal e social à socialização para o trabalho ${ }^{6-8}$.

A situação dos adolescentes que trabalham como aprendizes parece ser um campo fértil de estudo para aprofundar a compreensão sobre as representações do trabalho entre jovens e contribuir com a formulação de programas e políticas de inseção laboral de jovens. Além das garantias trabalhistas, os aprendizes recebem trainamento específico para o exercício de suas funções. Algumas dessas experiências vêm sendo desenvolvidas no âmbito de organizações não-governamentais (ONGs), entidades sem fins lucrativos e que prestam serviço à população, que oferecem programas de aprendizagem para adolescentes e jovens de comunidades populares. No entanto, até o presente momento não se conhece mais profundamente as formas como vem ocorrendo a inserção laboral dos adolescentes participantes desses programas, bem como as representações que desenvolvem sobre o trabalho a partir das práticas que exercem.

Este estudo explora as representações do trabalho entre jovens que participam de um programa de aprendizagem desenvolvido por uma ONG localizada em Salvador (BA), buscando estabelecer uma compreensão incial sobre a forma através da qual os adolescentes que participam de contextos formais e estruturados de trabalho, contando com garantias legais e treinamento específico para o exercício de suas funções, interpretam e significam a atividade laboral.

O estudo foi realizado a partir do referencial teórico da Teoria das Representações Sociais ${ }^{9-11}$. A noção de representação social diz respeito ao sistema de valores, idéias e práticas, com dupla função: primeiro, estabelecer uma ordem que possibilitará às pessoas oreintar-se em seu mundo material e social e controlá-lo; e, em segundo lugar, possibilitar que a comunicação seja possível entre os membros de uma comunidade, fornecendo-lhes um código para nomear e clas- sificar, sem ambigüidade, os vários aspectos de seu mundo e da sua história individual e social (Moscovici, , 2004 p.21).

As representações sociais podem ser consideradas como o conteúdo mental estruturado isto é, cognitivo, avaliativo, afetivo e simbólico - sobre um determinado fenômeno social relevante, ou sobre um assunto do seu cotidiano, que toma a forma de metáforas, e que é conscientemente compartilhado com outros membros do grupo social ${ }^{12}$. Nas palavras de Jodelet ${ }^{10}$, as representações sociais consistem num saber prático, cuja função é tornar o que não é familiar em algo familiar e próximo.

As representações sociais são indispensáveis para a compreensão do conhecimento social que orienta as práticas de uma determinada população, ou seja, o conhecimento que ela utiliza para atuar no cotidiano e interpretar a realidade e para encontrar seu lugar no mundo. Conforme destaca Abric ${ }^{13}$, as representações sociais atuam como um sistema de intepretação de realidade que organiza as relações do indivíduo com seu contexto, determinando seus comportamentos e práticas, servindo de guia para a ação.

De que forma os adolesentes aprendizes concebem o trabalho? Como eles vivenciam a relação entre trabalho e estudo? Qual a precepção que têm sobre o adolescente trabalhador? O presente trabalho busca examinar essas percepções, recuperando os elementos que as caracterizam. Pelo fato das representações sociais situarem o indivíduo dentro de um campo social, facilitando a elaboração de uma identidade pessoal e social, a compreensão de como o adolescente constrói representações de si mesmo e do trabalho é especialmente valiosa, pois a construção da identidade e a transição para o mundo do trabalho ganham grande destaque nesse momento da vida ${ }^{14}$. Por tratar-se de um referencial importante na construção da identidade de parcela significativa da população jovem, em especial aqueles de baixa renda, residentes nos grandes centros urbanos, o papel de "adolescente trabalhador" necessita ser mais detalhadamente investigado pelos pesquisadores da área da Psicologia. 


\section{MÉTODO}

\section{Participantes}

Os participantes deste estudo foram 71 adolescentes com idades entre 16 e 18 anos, inseridos no Programa Estúdio Aprendiz, realizado pela ONG CIPÓ - Comunicação Interativa, sediada em Salvador (Bahia), voltada para a promoção do desenvolvimento e inserção social de adolescentes e jovens. O Programa Estúdio Aprendiz tem duração de 18 meses e atende jovens moradores da periferia, que recebem quatro meses de formação inical na CIPÓ e são contratados por empresas de médio porte, onde passam quatorze meses exercendo funções na área de Comunicação, Gestão e Informática (assistentes de design gráfico e webdesign, atendimento ao público, assistentes administrativos, monitores de bibliotecas e laboratórios de informática).

Dentre os adolescentes que participaram desse estudo, 21 estavam cursando a formação inicial dado pela ONG, quinze estavam trabalhando há seis meses nas empresas e 32 estavam terminando o Programa de Aprendizagem após passarem 14 meses como aprendizes em empresas.

\section{Intrumento}

Para levantar as representações sociais dos adolescentes, foi aplicado um questionário especialmente desenvolvido para esse estudo. $\mathrm{O}$ questionário continha três questões abertas: Para você, o que é trabalho? O que significa para você ser adolescente e trabalhar? Como é para você estar estudando e trabalhando ao mesmo tempo?

\section{PROCEDIMENTO}

Os adolescentes responderam ao questionário em uma sala de aula da ONG CIPÓ Comunicação Interativa, como parte das atividades realizadas no âmbito do Programa Estúdio Aprendiz, sempre acompanhados por um educador que os informou sobre o estudo e leu as questões do intrumento em voz alta, indicando que os jovens deveriam responder a partir de suas experiências pessoais. Em seguida, os jovens ti- veram aproximadamente uma hora para responder livremente às questões.

\section{Análise dos Dados}

O procedimento utilizado para análise dos dados foi a análise de conteúdo. Após a leitura das respostas dadas pelos jovens, o material foi agrupado de acordo com os temas mais recorrentes resultados do trabalho, atitudes frente ao trabalho e desenvolvimento pessoal. Foram construídas três categorias e subcategoriais ressaltando os elementos mais significativos apontados pelos jovens em suas respostas. Em seguida, estas categorias e subcategorias foram agrupadas e distribuídas de acordo com a freqüência, dispostas numa tabela. Devido ao fato de que algumas respostas individuais foram duplamente categorizadas, o total de freqüências apresentadas excede o número de participantes que responderam aos questionários.

\section{RESULTADOS E DISCUSSÃO}

Os resultados apresentados a seguir seguem a ordem das perguntas do questionário respondido pelos jovens.

\section{O que é trabalho?}

Os adolescentes que participaram desse estudo descreveram suas representações do trabalho em torno de três grandes categorias: resultados do trabalho, atitudes frente ao trabalho e desenvolvimento pessoal.

Conforme a Tabela 1, a categoria que aparece mais freqüentemente nas respostas dos jovens relaciona o trabalho com os seus resultados (i.e.resultados do trabalho). Entre os aspectos mais centrais e relevantes a essa categoria encontram-se: obtenção de remuneração, dinheiro ou salário (18), execução de atividades ou tarefas e cumprimento de obrigações (17) e alcançar a sobrevivência ou sustento (14). Outros aspectos indicados com menos freqüência pelos participantes foram: o trabalho associado ao alcance de objetivos e metas (5) e o aumento do estresse (1). 
Tabela 1 - Representações Sociais do Trabalho entre Adolescentes Aprendizes

\begin{tabular}{|c|l|c|}
\hline CATEGORIA & SUBCATEGORIA & FREQUENNCIA \\
\hline \multirow{4}{*}{ Resultados do trabalho } & Obtenção de Salário/Remuneração/Dinheiro & 18 \\
\cline { 2 - 3 } & Execução de atividades ou tarefas/Cumprimento de obrigações & 17 \\
\cline { 2 - 3 } & Alcance da sobrevivência ou sustento & 14 \\
\cline { 2 - 3 } & Alcance de objetivos e metas & 5 \\
\cline { 2 - 3 } & Aumento do estresse & 1 \\
\hline Atitudes frente ao trabalho & Responsabilidade/Compromisso & 26 \\
\cline { 2 - 3 } & Competência/Capacidade & 5 \\
\cline { 2 - 3 } & Pontualidade & 2 \\
\cline { 2 - 3 } & Esforço/Dedicação & 2 \\
\cline { 2 - 3 } & Satisfação/Prazer & 25 \\
\hline Desenvolvimento pessoal & Aprendizagem & 7 \\
\cline { 2 - 3 } & Experiência & 131 \\
\hline
\end{tabular}

A representação do trabalho como forma de obter dinheiro ou remuneração pode ser ilustrada através do depoimento do participante (ss) \# 57. Ele indica que "o trabalho é algo que a pessoa faz [...] ganhando seu dinheiro de maneira honesta". Da mesma forma, o ss \# 51 relata que "o trabalho é algo que você faz e é remunerado" ou, conforme o participante \# 19 "trabalhar é um meio de [obter] renda para minha família". O trabalho como execução de atividades e cumprimento de obrigações destaca-se no depoimento do ss \# 56 "trabalho é você cumprir com suas obrigações" e, também, do ss \# 71 "trabalho é um ato que tem por objetivo [...] cumprir suas tarefas como forem estabelecidas". O trabalho associado à sobrevivência e ao sustento revala-se no depoimento do ss \# 69, para quem "trabalhar é fundamental, é a única forma de sobrevivermos nesse mundo" e do ss \# 37, que indica: "trabalhar é ter a capacidade de se sustentar".

Outra categoria bastante enfatizada pelos adolescentes pesquisados relaciona as atitudes que os jovens têm frente ao trabalho, ou que adquirem a partir do trabalho. Muitos adolescentes (26), ao refletirem sobre o significado do trabalho, referem-se às responsabilidades que passam a ter a partir do desempenho dessa atividade: acordar cedo, chegar na hora, cumprir tarefas, buscar fazer o melhor. Nesse sentido, a responsabilidade aparece como aspecto central e amplo, inerente ao próprio caráter do trabalho. O depoimento da ss \# 42 ilustra muito bem essa maneira de representar o trabalho: "trabalho é a responsabilidade que se adquire, tendo hora de chegar, plajenamento do trabalho diário, disposição para ajudar, força de vontade [...]." Outros aspectos que também se relacionam com essa categoria são competência e capacidade (9), pontualidade (5), esforço e dedicação (2) e satisfação e prazer (2). O ss \# 24 relata que, no trabalho, "a pessoa mostra que tem capacidade", ou "expressa o que você sabe" (ss \# 15), ou ainda "pratica o que você domina" (ss \# 21). Esses depoimentos ressaltam a associação entre trabalho e competência ou capacidade. O trabalho como esforço ou como satisfação aparece de maneira periférica para esses jovens.

A última categoria presente no relato dos aprendizes associa trabalho com desevolvimento pessoal. Aqui o elemento mais significativo é a possibilidade de aprendizagem (25), talvez pela própria natureza do Programa em que estão inseridos, que vincula o jovem ao mundo do trabalho através da Lei da Aprendizagem. Mas os jovens também relacionam o trabalho com a aquisição de experiência (7). Conforme relata o ss \# 50, "trabalhar é desenvolver as coisas que eu sei fazer e aprender as que eu não sei”. Ou, como indica o ss \# 40 "trabalho é um processo de amadurecimento pessoal, [...] que ajuda a desenvolver um ideal para o futuro", ou conforme a ss \# 34 "é um meio de conhecimento e crescimento pessoal". Buscando relacionar o trabalho com experiência, o ss \# 8 relata que o trabalho "[traz] novas experiências para meu futuro", ou como 
revela o ss \# 19 "o trabalho é um meio de adquirir experiência e maturidade".

\section{O que significa ser adolescente e trabalhar?}

Em suas respostas a essa questão, os adolescentes puderam se distanciar um pouco mais e refletir sobre o sentido do trabalho em suas vidas. As respostas reafirmam a centralidade dos elementos responsabilidade (30) e possibilidade de aprender coisas novas (26) nas representações dos jovens.

Em relação à responsabilidade, aparecem aspectos positivos e negativos. Os jovens revelam que o adolescente que trabalha precisa saber dividir o tempo entre estudo, trabalho e lazer, buscando conciliar essas diferentes atividades. Precisa ser organizado, saber administrar o tempo, ter força de vontade. Conforme relata o ss \# 52 "ser adolescente e trabalhar significa um aumento da responsabilidade [pois] o adolescente tem que conciliar escola, lazer e trabalho". Ou como indica o ss \# 39 "significa ter muita responsabilidade, saber que a hora da brincadeira acabou e assumir seus compromissos".

Os aspectos negativos da responsabilidade parecem estar associados com o cumprimento de obrigações que não são próprias da adolescência. Isso se confirma, por exemplo, no depoimento do ss \# 62, que revela: "ser adolescente é uma fase que queremos ter tudo, mas às vezes as condições dos pais não são muito boas e, então, o adolescente fica irritado, rebelde, mas não procura reconhecer o quanto a situação não está boa. [...] Ser adolescente pra mim é uma grande barra e ainda mais, [é preciso] saber dividir os horários de estudar e trabalhar. É muita responsabilidade que o adolescente carrega nas costas". Ou conforme revela o ss \# 22: "ser adolescente é muito bom, é a fase de se divertir, sair, brincar e a maioria [é] irresponsável. Mas quando entra o trabalho, tudo muda".

Outros depoimentos, no entanto, ressaltam o aspecto positivo da responsabilidade. A ss \# 58 indica que ser adolescente e trabalhar "significa ter muita responsabilidade, organizar a vida, não deixar as coisas de lado e sempre tentar resolver tudo no seu tempo determinado, saber sepa- rar as coisas e ter sempre certeza do que você está fazendo". A ss \# 50 revela que "ser adolescente e trabalhar significa [ter] reponsabilidade. E é bom, pois [a pessoa] já vai crescendo responsável, se preparando logo para o futuro". Ou ainda, como revela o ss \# 37 ser adolescente e trabalhar significa"ter [mais] responsabilidade do que antes e poder mostrar para nossos pais que temos capacidade de fazer o que eles menos esperam".

O aprendizado aparece também como um aspecto central da representasção do trabalho entre os adolescentes aprendizes. Conforme indica o ss \# 10 "ser adolescente e trabalhar é legal porque eu conheço muitas coisas e tiro minha conclusão de como vou trabalhar e me formar no futuro". Ou como revela o ss \# 15 "é muito bom, pois você aprende desde cedo sobre o mundo do trabalho e sabe como enfrentar o trabalho no futuro". O depoimento da ss \# 41 também revela muito bem esse aspecto do trabalho associado à oportunidade de aprender: "a adolescência é uma fase da nossa vida em que começamos a conhecer o mundo, tudo de bom e de ruim que ele tem a nos oferecer. E o trabalho é o [lado] bom do mundo, onde temos a oportunidade de crescer e aprender. Quanto mais cedo melhor, pois temos ajuda dos nossos pais, dos nossos amigos e isso nos faz crescer".

\section{Como é estar trabalhando e estudando ao mesmo tempo?}

Em suas respostas a essa questão, a maioria dos jovens revelou que trabalhar e estudar simultaneamente é difícil, pois exige o esforço de conciliação de diferentes atividades: estudo, trabalho e lazer. Dentre os adolescentes pesquisados, 33 revelam ter conseguido superar o desafio, organizando os horários, equilibrando o trabalho e a vida pessoal. Eles acreditam que esse esforço foi válido. O depoimento da ss \# 66 revela muito bem esse aspecto. Ela diz: "no início, achei que ia ser um pouco difícil, mas percebi que era uma questão de saber dividir o tempo. Deixo tudo em ordem nos finais de semana, para não sentir nenhum aperto durante a semana". Essa perspectiva é confirmada pelo ss \# 24, que 
indica: "no começo, foi muito difícil de estudar e trabalhar ao mesmo tempo, mas com o passar dos dias eu fui conciliando os dois e agora eu tenho mais tempo para fazer as coisas do que antigamente".

Outros jovens (31) indicam que é bom estar trabalhando e estudando. Embora reconheçam a dificuldade de conciliar as duas atividades, encaram o processo de maneira positiva, como uma oportunidade de desenvolver a flexibilidade, de se organizar melhor, de planejar o dia-a-dia. Alguns jovens indicam, também, que o trabalho os estimulou a estudar e aprender mais. O depoimento do ss \# 40 expressa o que pensam e sentem esses adolescentes: "Estar trabalhando e estudando ao mesmo tempo é [bom], pois desenvolve o senso criativo, social e a flexibilidade para lidar com a rotina do dia-a-dia". Conforme indica o ss \# 8, "foi ótimo trabalhar e estudar; gostei bastante desse tempo corrido e não me atrapalhou em nada, porque antes eu fazia meu planejamento". Ou ainda, como relata o ss \# 16 "não tive dificuldade em trabalhar e estudar. Depois que comecei a trabalhar, me deu mais vontade de estudar. Isso me mostrou que trabalhar não atrapalha o estudo se a pessoa tem vontade de trabalhar".

Alguns jovens (11), no entanto, revelam que conciliar trabalho e estudo é muito difícil e cansativo. Para eles falta tempo para estudar, e além disso, não conseguem chegar na escola no horário, ou se alimentar direito. Conforme revela a ss \# 35, "é muito difícil tarabalhar e estudar porque acho que tenho pouco tempo para os estudos, além de estudar longe de casa". Ou como indica o ss \# 10: "é muito difícil [conciliar as duas atividades], porque eu não tenho muito tempo para estudar em casa [...] é muito cansativo".

\section{CONSIDERAÇÕES FINAIS}

Esse estudo aborda as representações sociais que 71 adolescentes aprendizes participantes de um programa de aprendizegem desenvolvido por uma ONG de Salvador têm sobre o trabalho. Os resultados indicam a complexidade da compreensão do trabalho por parte dos adolescentes e revelam que essa atividade não é representada de forma intrinsecamente positiva ou negativa pelos jovens. As representações variam de acordo com as interpretações que eles elaboram das suas experiências enqunto adolescentes trabalhadores.

De acordo com as informações analisadas, a representação acerca de trabalho entre os adolescentes pesquisados apresenta-se dentro de três grandes categorias: os resultados do trabalho, as atitudes frente ao trabalho e o desenvolvimento pessoal. Conforme indicam $\mathrm{Sá}^{10}$ e $\mathrm{Abric}^{13}$, as representações sociais se organizam em torno de um núcleo central, que lhes dá significado, e de elementos periféricos. As respostas dadas pelos jovens revelam que o núcleo central da representação que têm do trabalho é composto por elementos que identificam essa atividade com o cumprimento de tarefas e com a possibilidade de obter uma remuneração capaz de contribuir para a sobrevivência e o sustento de si mesmos e suas famílias. Além disso, os jovens ressaltam que o trabalho acarreta, por um lado, um aumento considerável nas responsabilidades assumidas no dia-a-dia, mas também possibilita o desenvolvimento e o aprendizado de conheicmentos novos. Esse resultado indica que os adolescentes aprendizes tendem a adotar uma representação objetiva e prática do trabalho, que nasce do contexto sócio-histórico em que vivem os adolescentes das periferias brasileiras. Ali suas necessidades de sobrevivência se apresentam de maneira contundente, levando os jovens a buscarem obter renda para ajudar o sustento de suas famílias.

Estudos anteriores sugerem que alguns elementos associados ao trabalho precoce trazem conseqüências negativas para a vida dos adolescentes $^{1,5}$. Um dos elementos apontados nesses estudos é o aumento da responsabilidade. No entanto, os resultados aqui relatados sugerem que o aumento da responsabilidade pode ser vivenciado pelos adolescentes tanto sob o lado positivo quanto negativo, a depender de como interpretam suas experiências. Por exemplo, alguns aprendizes indicam que o aumento da responsabilidade contribui para que se tornem mais organizados, mais ativos, planejem melhor suas atividades. Revelam que estão estudando e 
aprendendo mais. Outros adolescentes apontam que o aumento da responsabilidade os torna mais cansados e dificulta seus estudos. Nesse sentido, é possível afirmar que os resultados desse estudo corroboram com as pesquisas de AlvesMazotti ${ }^{4}$ e apontam para a diversidade das representações do trabalho entre os adolescentes.

Ao lado dos elementos centrais acima referidos, encontram-se elementos periféricos como a possibilidade de alcançar objetivos e metas, o aumento da competência, da pontualidade, o esforço e dedicação, a satisfação e o prazer de trabalhar, a oportunidade de ter mais experiência, mas também o aumento do estresse. Esses elementos indicam o que é particular na vivência de cada jovem em relação ao trabalho.

Quando refletem sobre a relação entre ser adolescente e trabalhar, a maioria dos jovens aponta a responsabilidade e a possibilidade de aprender e de se desenvolver como aspectos relevantes. Essas respostas refoçam a centralidade desses elementos na representação social do trabalho entre os adolescentes pesquisados. É provável que o forte impacto da resposabilidade esteja associado ao momento em que essa experiência é vivenciada pelos participantes da pesquisa, ou seja, a adolescência. Alguns dos participantes apresentaram uma concepção da adolescência mais próxima da infância, como um momento de querer tudo, ou seja, de ter muitas expectativas, de experimentar coisas novas, mas também asssociado com brincadeiras, com "curtir a vida". Nesses casos, a entrada no mundo do trabalho parece representar uma ruptura, uma mudança radical na vida do jovem. A maioria dos participantes, no entanto, apresenta uma visão da adolescência mais próxima da vida adulta. Aqui, a responsabilidade parece justamente estar associada ao processo de amadurecimento pelo qual o adolescente está passando e no qual a experiência de trabalho tende a atuar como catalizadora.

Ainda no que se refere à relação entre ser adolescente e trabalhar, a ênfase dada pelos jovens à aprendizagem e ao desenvolvimento parece decorrer do fato deles estarem participando de um Programa de Aprendizagem. Esse contexto favorece a aprendizagem e torna rele- vante o aspecto da aprendizagem que acontece na ONG e também na empresa, aparecendo de forma marcante nos depoimentos dos jovens. Talvez outros jovens, submetidos a outro tipo de programa de inserção laboral que não seja necessariamente um programa de aprendizagem, ou que se insiram no mundo do trabalho por conta própria, desenvolvam uma representação do trabalho na qual a aprendizagem não seja um aspecto tão relevante. Pesquisas futuras, comparando as representações sociais de adolescentes aprendizes com as dos adolescentes que não se encontram em programas desse tipo, podem esclarecer melhor esse ponto.

Por fim, quando perguntados sobre a relação entre trabalhar e estudar ao mesmo tempo, a maioria dos jovens revela ter consciência das dificuldades em conciliar as duas atividades, mas acredita que esse esforço é válido e tem caráter positivo. Essas respostas corroboram estudos anteriores que apontam para a existência de contradições nas representações dos jovens em situações envolvendo trabalho e estudo. Mas que, ainda assim, predomina o valor afirmativo do trabalho para o futuro ${ }^{1}$.

Tomados em seu conjunto, os resultados desse estudo piloto revelam que o trabalho na adolescência, desde que realizado em situação de aprendizagem, com todas as garantias legais, pode ter efeitos positivos e promover o desenvolvimento e o amadurecimento dos jovens. Entretanto, é preciso ter cautela no desenho dos programas de inserção laboral para essa faixa etária. $\mathrm{O}$ acompanhamento e o apoio dado aos jovens, em todas as etapas, por profissionais qualificados é essencial para que eles possam fazer uma transição saudável para o mundo do trabalho, sem comprometer outros aspectos importantes do seu desenvolvimento, como a escolaridade e o lazer.

A conciliação entre trabalho e estudo aparece como um aspecto delicado. Embora alguns autores apontem os aspectos negativos que o trabalho acarreta para a vida escolar dos jovens ${ }^{3,7}$ é possível criar condições favoráveis para o exercício do trabalho concomitante ao estudo. Por um lado, os próprios jovens apontam para a necessidade de saber organizar-se, de aprender a conciliar as atividades, de ter determinação. Es- 
ses aspectos devem ser estimulados e desenvolvidos de forma explícita nos programas de aprendizaegm, através de atividades especialmente direcionadas para essa finalidade. Por outro lado, ao desenhar programas dessa natureza, é preciso pensar em criar melhores condições de estudo, para os jovens que trabalham. No âmbito das políticas educacionais, podem ser criados mecanismos e programas que atendam as necessidades específicas dos jovens que trabalham, oferecendo, por exemplo, atividades complementares de apoio pedagógico nas escolas, possibilitando a aquisição de créditos extras, possibilitando ao jovem exercer as duas atividades.
Esse estudo aponta para a necessidade de aprofundar as pesquisas nesse campo como forma de favorecer o desenvolvimento dos jovens que necessitam trabalhar e estudar ao mesmo tempo. Além disso, ele possibilita compreender a relevância do trabalho para o desenvolvimento e a socialização dos jovens de classes populares. O estudo amplia a idéia de Alves-Mazzotti ${ }^{4}$ de que o trabalho pode contribuir para que o adolescente desenvolva sentimentos de independência e auto-valorização, desde que seja exercido em condições favoráveis ao desenvolvimento humano, sem o prejuízo de outras atividades fundamentais à vida saudável.

\begin{abstract}
The present study investigated adolescent apprentices' social representations of work and its relationship to study. Seventy adolescents, with ages raging from 15 to 18 years old, participating in an apprenticeship program developed by a NGO in Salvador (Bahia), answered an open-ended questionnaire that contained the following questions: What does work mean to you? What does it mean to be a working adolescent? How do you feel about studying and working at the same time? The answers were submitted to a content analysis for the main themes. Findings point to 3 types of social representation of work among apprentice adolescents: work outcomes, work attitudes, and personal development. Aspects such as financial earnings (i.e. wage) and task performance emerged as work outcomes. Among the work attitudes, the most significant were responsibility and competence development. In the domain of personal development, aspects such as learning and acquisition of experience were relevant. The relationship between working and studying appears to be a complex one, demanding conciliation efforts on the part of adolescents, but it does not necessarily have a negative connotation.
\end{abstract}

Key words: Adolescent. Adolescent Development. Work. Child Labor.

\section{REFERÊNCIAS}

1. Oliveira DC, Fischer FM, Martins IS, Teixeira LR, Sá C. Futuro e liberdade: o trabalho e a instituição escolar nas representações sociais de adolescentes. Estud Psicol (Natal). 2001;6(2):245-58.

2. Fischer FM, Martins IS, Oliveira DC, Teixeira LR, Latorre MD, Cooper S. Occupational accidents among middle and high school students of the state of São Paulo, Brazil. Rev Saúde Pública. 2003;37(3):351-6.

3. Martins IS, Fischer FM, Oliveira DC, Teixeira LR, Costa LR, Marinho SP, et al. Crescimento e trabalho de estudantes de ensino fundamental e médio em São Paulo, Brasil. Rev Saúde Pública. 2002;36(1):19-25.
4. Alves-Mazzotti AJ. Trabalho infanto-juvenil: representações sociais de meninos trabalhadores, seus pais, professores e empregadores. In: Paredes AM, Oliveira DC, editores. Estudos interdisciplinares de representação social. Goiânia: AB; 1998. p. 285-302.

5. Oliveira DC, Fischer FM, Amaral MA, Teixeira MC, Sá CP. Positividade e negatividade do trabalho nas representações sociais de adolescentes. Psicol Reflex Crít. 2005;18(1):125-33.

6. Arnett JJ. Learning to stand alone. Hum Dev. 1998;41(5-6):295-315.

7. Sarriera JC, Câmara SG, Berlim CS. Elaboração, desenvolvimento e avaliação de um programa de inserção ocupacional para jovens desempregados. Psicol Reflex Crít. 2000;13(1):189-98. 
8. Sarriera JC, Silva MA, Kabbas CP, Lopes VB. Formação ocupacional em adolescentes. Estud Psicol (Natal). 2001;6(1):27-32.

9. Moscovici S. Representações sociais: investigações em psicologia social. Rio de Janeiro: Vozes; 2004.

10. Sá CP. Núcleo central das representações sociais. Rio de Janeiro: Vozes; 1996.

11. Jodelet D. Representações sociais: um domínio em expansão. In: Jodelet D, editor. As representações sociais. Rio de Janeiro: EdUERJ; 2001.p. 17-44.
12. Wagner W. Descrição, exploração e método em representações sociais. In: Guareschi P, Jovchelovitch $\mathrm{S}$, editores. Textos em representações sociais. Rio de Janeiro: Vozes; 1995. p. 149-86.

13. Abric JC. O estudo experimental das representações sociais. In: Jodelet D, editor. As representações sociais. Rio de Janeiro: EdUERJ; 2001.p. 155-7.

14. Arnett JJ. Adolescents' uses of media for selfsocialization. J Youth Adolesc. 1995;24(5):519-34.

Recebido em: 23/06/2006 Aprovado em: 11/09/2006 